\title{
Sosyal Hizmet Uygulamalarında Aile Dayanıklılığına Etki Eden Faktörler
}

\author{
Factors Affecting Family Resilience in Social Work Practices
}

\author{
Arş. Gör. Dr. Kübra ARSLAN (iD),
}

\begin{abstract}
$\ddot{\mathbf{O} z}$
$\mathrm{Bu}$ çalışmada ailelere yönelik gerçekleştirilen sosyal hizmet uygulamalarında ailelerin dayanıklılığına etki eden faktörlerin ele alınması amaçlanmaktadır. Aileler ile gerçekleştirilen sosyal hizmet uygulamalarında, ailenin yapısı, aile üyelerinin biyo-psiko-sosyo-kültürel bağlamları içinde yaşadıkları çevre göz önünde bulundurularak değerlendirilmektedir. Sosyal hizmet uygulaması, her bir aile üyesinin beklentileri, gereksinimleri ve problemlerini açığa çıkararak, ailenin sağlıklı bir aile ortamı oluşturmasına yardım etmeyi içermektedir. Aile dayanıklılığı yaklaşımı, ailenin güçlü yönlerine ve potansiyeline odaklanmakta ve aile üyelerini destekleyici bir ekip çalışması ile yaşanan olumsuz etkileri azaltmayı ve aile gelişimini desteklemeyi vurgulamaktadır. Aile dayanıklılığında, ailelerin yaşadığı zorlu süreçlere karşı koyma, baş etme, yeniden toparlanma gücü ve yeteneğinin olduğu ileri sürülmektedir. Ailelere yönelik gerçekleştirilen sosyal hizmet uygulamalarının temeli aile içinde yaşanan zorluk durumunun belirlenmesi, aile ilişkilerinin ortaya çıkarılması, ailelerin güçlü ve güçsüz yönlerinin fark edilmesi kısacası aileyi harekete geçirmedir. Böylece ailelerin yaşanan zorluk durumu ile baş etmesi mümkün olacaktır. Bu bağlamda gerçekleştirilen sosyal hizmet uygulamalarında kullanılan aile dayanıklılığında; ailenin inanç sistemleri, pozitif bakış açıları, birbirlerine karşı esnek olmaları, karşıllıklı destek ve iş birliği içinde olmaları, kaynakları harekete geçirecek güçte olmaları, açık ve tutarlı iletiler ile ortak sorun çözme becerilerinin gelişmiş olmasının etkili olduğu açığa çıkarılmıştır. Ailelerin bu beceriler sayesinde dayanıklılıklarının artması öngörülmektedir. Gelecek çalışmalarda ailelerin yaşanan zorlukların üstesinden gelmesi ve dayanıklılığını arttırması için diğer sistem ve kaynaklarla olan ilişkilerinin ele alınması önerilmektedir.
\end{abstract}

Anahtar Kelimeler: Sosyal hizmet, sosyal hizmet uygulamaları, aile, aile dayanıklılı̆g 1

Makale Türü: Derleme

\begin{abstract}
In this study, it is aimed to address the factors affecting the resilience of families in social work practices for families. In social work practices carried out with families, family structure, bio-psycho-socio-cultural contexts of family members is evaluated by considering the environment in which they live. Social work practice includes helping the family to create a healthy family environment by revealing the expectations, needs and problems of each family member. The family resilience approach focuses on the strengths and potential of the family and emphasizes reducing the negative effects experienced and supporting family development with a supportive teamwork for family members. It has been suggested that family resilience has the power and ability to resist, cope with the difficult processes experienced by families, and to recover again. The basis of social work practices for families is determining the difficulties experienced in the family, revealing family relations, recognizing the strengths and weaknesses of families, in short, mobilizing the family. Thus, it will be possible for families to cope with the difficult situation. In family resilience used in social work practices in this context; It has been revealed that the belief systems of the family, their positive perspective, being flexible towards each other, being mutually supportive and cooperative, strong enough to mobilize resources, developed common problem-solving skills with clear and consistent messages have been revealed. Through these skills, families are expected to increase their
\end{abstract}

${ }^{1}$ Kırıkkale Üniversitesi, Sağlık Bilimleri Fakültesi, kbraarslann@gmail.com.

Atıf için (to cite): Arslan, K. (2021). Sosyal hizmet uygulamalarında aile dayanıklılı̆̆ına etki eden faktörler. Afyon Kocatepe Üniversitesi Sosyal Bilimler Dergisi, 23(2), 365-374. 
resilience. In future studies, it is recommended that families' relationships with other systems and resources should be addressed in order to overcome difficulties and increase their resilience.

Keywords: Social work, social work practices, family, family resilience

Paper Type: Review

\section{Giriş}

Aile, geleneksel olarak anne-baba ve çocuklardan oluşan aralarında biyolojik, psikolojik, duygusal ve sosyal bağ bulunan toplumun en küçük yapı birimidir. Davranışın biçimlenmesi ve etkilenmesinde ailenin önemi tartışmasızdır. İnsan, yaşadığ çevre ve davranışlarını içeren bireyin bütünlüğü sosyal hizmetin odağıdır (Bulut, 1993). Koşar (1992)'a göre sosyal hizmet uzmanının; ailenin sosyal, kültürel ve ekonomik durumlarını inceleyerek, üyelerin özelliklerini belirleme, işleyişlerini sosyal çevreleri ile el alma ve kendi içinde yaşadıkları dünyalarını anlama görevleri bulunmaktadır. Her aile bir sistem olarak değerlendirilmekte ve ailelerin gelişim süreçlerini tamamlamalarına destek olunmaktadır.

Ailelerle gerçekleştirilen sosyal hizmetin temel amacı, aile üyelerinin gereksinimlerini karşılayabilmeyi öğrenebilmeleri için ailelere destek olmaktır. Bu bağlamda ailelerle sosyal hizmet uygulamasında, ailelerin güçlerini pekiştirmenin yanı sıra ailelerin işlevselliklerinin artması için çalışmalar yapılarak, aileye yönelik somut değişiklikler içeren destekler sağlanmaktadır (Duyan, 2003).

Collins, Jordan ve Coleman (2013)'a göre ailelerle sosyal hizmet uygulamasının amacı şu şekildedir:

- Ailenin güçlü yönlerini açığa çıkartmak.

- Günlük rutinlerin devam edebilmesi için aile fonksiyonlarında ciddi değişiklikler yapmak.

- Aile terapisinin ardından ailelerin aile fonksiyonlarını devam ettirebilmesi için destek sağlamak.

- Aile ve çevresi arasında üyelerin en temel ihtiyaçlarının karşılanacağı ilişki kurmalarını sağlamak.

Aileye yönelik sosyal hizmet müdahalesi, her bir aile üyesinin beklentilerini gereksinimlerini ve problemlerini açığa çıkararak ailenin sağlıklı bir aile ortamı oluşturmasına yardım etmeyi içermektedir. Aileler ile çalışırken ailenin içinde bulunduğu durum, yaşanılan kriz ve bu krizle başetmede aile dayanıklılığı kavramı karşımıza çıkmaktadır. Aile dayanıklılığı, yaşanılan kriz durumlarında aile üyelerinin sürece aktif katılımları ile yetkinlik geliştirdiği, uyum sağlama becerisi olarak ifade edilmektedir. Sosyal hizmet uygulamalarında aile dayanıklılığının önemine değinilen bu çalışmada, aile dayanıklılığına etki eden faktörlerin ele alınması amaçlanmıştır.

\section{Yöntem}

$\mathrm{Bu}$ çalışmada ailelerin dayanıklılığına etki eden faktörler, ailelerle sosyal hizmet uygulaması, aile dayanıklılı̆̆ 1 , aile dayanıklılık faktörleri, aile dayanıklılık modeleri ve sosyal hizmet uygulamalarında aile dayanıklılığı yaklaşımın önemi kapsamında teorik bir çerçevede sunulmuştur.

\section{Ailelerle Sosyal Hizmet Uygulaması}

Zastrow (2015)' a göre sosyal hizmet müdahalesinin mikro uygulama düzeyini aile sistemi oluşturmaktadır. Aile müdahalesinde sosyal hizmetin işlevleri müracaatçıyı güçlendirerek danışmanlık, kaynaklarla müracaatçıların bağlantılarını sağlayarak kaynak yönetimi ve eğitim olarak belirlenmiştir. Bu bağlamda ailelerle gerçekleştirilen sosyal hizmet 
uygulamasının aile danışmanlığı, aile eğitimi ve savunuculuk olmak üzere üç boyutu bulunmaktadır.

\subsection{Aile danışmanlı̆̆ı}

Aile danışmanlığı, bireysel danışmadan önemli düzeyde farklılık göstermektedir. Aile danışmanlığında bir birey yerine bütün aile üyeleri aynı anda ortak danışmaya alınmakta ve çok boyutlu olarak ailelerin ihtiyaçları ve amaçları ele alınmaktadır (Özgüven, 2001). Koşar (1992), tedavi ve danışma hizmetlerinin daha çok sorun çözmeye yönelik olduğunu, bu tür çalışmaların inceleme, değerlendirme ve bunlara dayalı tedavi planı belirleme ve uygulama sürecini içerdiğini vurgulamaktadır.

\subsection{Aile eğitimi}

Aile üyelerinin ilişkilerini güçlendirmek ve karşılıklı olarak sorumluluklarını daha iyi yürütebilmeleri noktasında aile eğitimleri önem taşımaktadır (Koşar, 1992). Aile eğitimindeki temel amaç, aile üyelerinin bilgi, beceri ve davranışları ile gelişimlerinin olumlu yönde etkilenmesinin sağlanmasıdır.

\subsection{Savunuculuk}

Kirst-Ashman ve Hull (1999)'a göre işsizlik, düşük ekonomik düzey, yaşanılan yerin uygun olmaması, ulaşım, sağlık gibi olanakların yetersiz olması aileler üzerinde olumsuz etki oluşturmaktadır. Bu koşullarda sosyal hizmet uzmanlarının savunuculuk rolleri ön plana çıkmaktadır. Aileler ile birlikte uygun hizmetleri araştırmak, kaynaklar ile ailelerin bağlantılarının kurulmasını sağlamak oldukça önemlidir. Sosyal hizmet uzamanı savunucu rolünde müracaatçının haklarını korumak için de hareket etmekte ve arabulucu gibi faaliyet göstermektedir (Duyan, 2003).

\section{Aile Dayanıklılığı}

Latince resiliens sözcüğünden türeyen dayanıklılık (resilience) kavramı bir maddenin bükülür ya da esnek olmasını ifade etmektedir (Greene ve Conrad, 2002). Walsh (2016)'e göre dayanıklılık, zor bir durumla karşılaşıldığında güçlü bir şekilde başetmeyi, zorluk durumunda gelişmeyi ve dirençli olmayı sağlayan aktif katılımın gerekli olduğu bir süreç olarak tanımlanmaktadır.

Dayanıklılık aile açısından ele alındığında, zor durum karşısında aile içinde uyum sağlama, ayakta kalabilme ve sağlıklı aile işleyişini sürdürme ya da geliştirme becerisi olarak tanımlanmaktadır (Hawley, 2000; Patterson, 2002). Walsh (2016)'a göre aile dayanıklılı̆̆ ailenin direnç özellikleri ile hayat boyu devam eden aktif bir süreçtir.

Yaşam dönemleri içinde karşılaşılan zorlu süreçlerin ya da krizlerin atlatılarak aile döngüsünün devamlılığının sağlanması da aile dayanıklılığı olarak tanımlanmaktadır (Black ve Lobo, 2008). McCubbin, Thompson ve McCubbin (1996)'e göre aile dayanıklılığı, yaşanan kriz durumlarına uyum sağlayarak, zorluklara rağmen direnç gösteren ailelerin özelliğidir.

Aile dayanıklılığ1; zorluk/krizlerin süresi, zorluk/krizle karşılaşılan zaman, bu süreçte yararlanılan sosyal destek olmak üzere üç boyutta açıklanmıştır (Simon, Murphy ve Smith 2005). Bu bağlamda, bu süreçte gerçekleştirilecek aileleri güçlendirme çalışmaları oldukça önemlidir.

\subsection{Aile Dayanıklılık Faktörleri: Koruyucu ve İyileştirici Faktörler}

Ailelere yönelik yapılan çalışmalarda, önemli olan kriz durumları olduğu kadar riskli durumlarda da aile sisteminin nasıl korunduğu ve iyileştirici hale geldiğini belirlemektir. Buna göre koruyucu ve iyileştirici faktörler aşağıdaki gibi ele alınmaktadır (McCubbin vd., 1997):

- Problem çözmeye ilişkin iletişim: Ailelerin yaşamlarındaki olaylara ve değişimlere karşı iletişim içinde olması başetme becerilerinin gelişmesini sağlamaktadır. 
- Eşitlik: Cinsiyet farklılı̆̆ gözetmeden eşitlik kavramında kendine güvenmek ve bağımsızlık aileleri güçlendirmede önemli bir rol oynamaktadır.

- Maneviyat: Dini ya da kültürel inançlar ailelerin krizleri farklı yorumlamalarına olanak sağlamaktadır.

- Esneklik: Kriz durumlarında ailelerin uyumu ve dengeyi sağlamaları için yaşam biçimlerini, görev ve sorumluluklarını, aile içi kurallarını ve rollerini değiştirmeleri gerekmektedir.

- Açıksözlülük: Dengeli iletişim ailelerin anlaşma ve dengeyi korumasının temelini oluşturmaktadır. Sağlıklı ailelerdeki iletişim doğrudan, dürüst, açık ve özgündür.

- Umut: Ailede, aile sistemi tehdit eden birtakım olaylar veya değişiklikler yaşayan üyelerin daha çok ümitsizlik ya da belirsizlik yaşadığı gözlemlenmektedir.

- Ailenin dayanıklılı̆̆: Kriz veya risk faktörleri ile karşılaşan ailelerin aile sistemlerinin sınırları zorlanmaktadır. Ailenin ortak güçlerini ve amaçlarını birleştirerek iş birliği yapması ve bu konuda kendilerine güvenmeleri gerekmektedir.

- Ailenin beraber geçirdiği zaman ve alışkanlıklar: Aile üyeleri, uyum ve denge ortamını oluşturmak amacı ile birlikte zaman geçirmeye ve günlük aktivitelere yer vermeye çalışmaktadır.

- Sosyal destek: Duygusal destek, sayg1 görme desteği, iletişim desteği, takdir edilme desteği ve özveri desteği koruyucu bir bağlılık ve ait olma duygusu gibi sosyal destekleri içermektedir.

- Sağlık: Aile üyelerinin fiziksel veya ruhsal sağlığının korunması ile dayanıklılığın geliştirilmesini içermektedir.

\subsection{Walsh'ın Aile Dayanıklılık Modeli}

Walsh (2016) geliştirdiği modelin temelini gelişimsel ve ekolojik bakış açısı ile beraber sistemik aile teorilerine dayandırmaktadır. Aile dayanıklılığı yaklaşımının en temel özelliği zorluklarla başetmek için kullanılan güçlü yanlara odaklanma görüşüdür. ele almıştır.

Walsh (2016), aile dayanıklılık modelini, Tablo1'de belirtildiği gibi üç temel düzeyde

Tablo 1. Dayanıkl1lik modeli

\begin{tabular}{|c|c|c|}
\hline İnanç Sistemleri & Örgütsel Süreçler & İletişim Süreçleri \\
\hline 1.Zorluklara verilen anlam & 4. Uyum sağlama esnekliği & 7. Açık ve Tutarlı İletiler \\
\hline 2. Pozitif Bakış Açısı & 5. Bağlantı, Karş1lıklı Destek & 8. Duygusal Paylaşım \\
\hline 3. Tinsellik & $\begin{array}{l}\text { 6. Sosyal ve } \\
\text { Kaynaklar }\end{array}$ & 9. Ortak Sorun Çözme \\
\hline
\end{tabular}

Kaynak: Walsh Aile Dayanıklılık Modeli (2016)

\subsubsection{Ailenin İnanç Sistemleri}

1. Zorluklara verilen anlam

- Dayanıklılığın ilişkisel görünümü- "zorlu birey” e karş1

- Zorluğun bulunan bağlam kapsamında ele alınması, normalleştirilmesi: Ortak anlaşılabilir durumların olması

- Tutarlılık duygusu: Krizin ortak anlamlı, anlaşılabilir, yönetilebilir bir mücadele olarak görülmesi. 
- Kolaylaştırıcı değerlendirme: Açıklayıcı özellikler, gelecek beklentilerin olması.

2. Pozitif bakış açısı

- Ümit ve iyimser eğilim: Zorlukların üstesinden geleceğine dair güven.

- Cesaretlendirme: Güçlü yönleri görüp söyleme ve potansiyellere odaklanma

- Aktif girişimci olma ve azim.

- Olasıllklar üzerinde uzmanlaşma: Neyin değiştirilemeyeceğini kabul etme; belirsizliğe tahammül etme.

3. Tinsellik

- Daha büyük değerler ve amaçlar.

- Maneviyat: İnanç, tefekkür uygulamaları, ritüeller, doğa ile bütünleşme ve ilişki kurma.

- İlham: Zihninde yeni olasılıklar canlandırma, hayaller kurma, yaratıc1lığı ifade etme, sosyal eylemler.

- Dönüşüm: Krizden öğrenme, değişim ve pozitif büyüme.

Ailenin inanç sistemleri tüm aile işleyişinin merkezindedir ve aile dayanıklılığında oldukça etkilidir. Ailelerde, mesleklerde ve topluluklardaki kimlikler paylaşılan inanç sistemleri ile gelişmektedir. Bu bağlamda inanç sistemleri, duygusal tepkileri tetikleyen, kararları bildiren ve eylemleri yönlendiren bir dizi temel öncül oluşturmak için bir araya gelen değerler, tutumlar, önyargılar ve varsayımları kapsamaktadır (Wright ve Bell, 2009).

Aileler, zaman içinde ortak inançlar inşa etmekte ve her ailenin ortak inancı kültürel değerlere bağlı olarak zaman içinde sosyal yaşamdaki konum ve deneyimlerden etkilenmektedir. Ailenin inanç sistemleri yaşanılan zorluk ve stres karşısında aileyi olumlu ve olumsuz şekilde etkilemektedir. Bu etkilenme biçimi ailenin inançlarının kolaylaştırıcı ve kısıtlayıcı olmasıyla yakından ilişkilidir. Kolaylaştırıcı inançlar, ailenin sorunlarını azaltarak çözüm seçeneklerini arttırırken; kısıtlayıcı inançlar, ailenin sorunlarını arttırmakta ve çözüm seçeneklerini azaltmaktadır. Ailede inanç sistemleri tutarlılık sağladığında, üyelerin kriz durumlarını anlamaları ve üstesinden gelmeleri kolaylaşacaktır (Walsh, 2016).

Walsh (2016)'e göre aileler, sorunlarını bir bağlam içerisinde görebildiklerinde bir bakış açısı kazanmakta ve sorunları normalleştirerek dayanıklılıklarını arttırmaktadır. Sorunları gelişimsel bir bağlamda görmek dayanıklılığı kolaylaştırmaktadır. Ayrıca aile üyeleri içinde pozitif bakışı açısına sahip bireyin olması tüm ailenin bakış açısını etkilemektedir. Pozitif bakış açısının aileye kazandırılmasında, aile üyelerinin birbirlerinin güçlü özelliklerini fark etmeleri, birbirlerini onaylamaları ve cesaretlendirmeleri gerekmektedir.

Manevi inanç ve deneyimlerde kurulan anlam, amaç ve bağlantı yolları geçmişten geleceğe nesiller arasında süreklilik sağlamaktadır. Din, ortak gelenekler, doktrin, ahlaki değerler ve uygulamalar, bir topluluk ve Tanrı ya da daha yüksek bir güç inancına sahip bir örgüt, kurumsallaşmış bir inanç sistemini ifade etmektedir. Tinsellik bu noktada devreye girmekte ve bütün inanç gelenekleri, iyileşme ve esneklikte şefkat ve bağışlama konusunda danışmanlık yapmaktadır. Geniş ve kapsamlı bir yapı olan tinsellik, günlük yaşamda ve ilişkilerde yaşanan aşkın inanç ve uygulamaları anlatmaktadır. Manevi inanç ve uygulamalar ailelere özellikle yaşanan zorluklar karşısında anlam, destek ve rahatlık sunmaktadır. Güçlü inanç ailelerin zorluklara dayanma, zorlukların üstesinden gelme ve yaşamları döndürme çabalarını desteklemektedir (Werner ve Smith, 2001). 


\subsubsection{Ailenin Örgütsel Süreçleri: Illişkisel ve Yapısal Destekler}

4. Esneklik

- Yeni zorluklarla başetmek için toparlanma, yeni durumlara uyum sağlayabilme ve değişime açık olma.

- Yeniden düzenleme, bozulma ile istikrarı yeniden kazanma: Süreklilik, güvenilirlik, öngörülebilirlik.

- Güçlü demokratik liderlik: Besleyen, rehberlik eden ve koruyan bir liderin olması.

- Çeşitli aile şekilleri

- Çift /ortak ebeveynlik ilişkileri: Karşılıklı saygı; eşit ortaklar

5. Bağlantı- Karşılıklı Destek

- Karş1lıklı destek, iş birliği ve bağlılık.

- Bireysel ihtiyaçlara, farklılıklara saygı gösterme.

- Yeniden bağlantı kurma, kırılan ilişkileri ve şikayetleri onarma.

6. Sosyal ve ekonomik kaynakları harekete geçirme

- Akrabalar, sosyal ve toplumsal destekleri harekete geçirme, uzman ve danışmanların olmasi

- Finansal güvenliğin sağlanması; stresli iş ve ekonomik zorluklar karşısında denge kurabilme.

- Daha büyük sistemlerin desteği: kurumsal ve yapısal destekler.

Walsh (2016)'e göre farklı formlarda ilişki ağları olan aileler, aile birimi ve üyelerinin bütünlügü̈, uyumu ve devamı için destekleyecek bir yapıya, kaynaklara ve organizasyona ihtiyaç duymaktadır. Ailenin örgütsel süreçleri, içsel ve dışsal normlardan, değişimlerden, sosyo-kültürel ve aile inanç sistemlerinden etkilenmekte ve sürekli değişim gösterebilmektedir. Krizlerle etkili bir şekilde baş etmek için ailelerin kaynaklarını harekete geçirme ve organize etme, stresi bastırma ve değişen koşullara uyacak şekilde aileyi yeniden örgütlemek gerekmektedir. Ailelerin bu örgütsel süreçlerinde meydana gelen değişimlere ve kriz durumlarına uyum sağlayabilmeleri için esnek olmaları gerekmektedir. Tüm sistemlerde olduğu gibi aileler sistemi de değişime direnme eğiliminde olmaktadır; ancak değişim kaçınılmaz bir durumdur. Bu noktada aileler hem beklenen hem de beklenmedik bir biçimde değişen gelişimsel ve çevresel taleplere uyum sağlayabilmelidir. Denge ve değişim arasındaki dinamik bir denge olan esneklik, ailelerin yapısını korumayı sağlarken, aynı zamanda yaşamın zorluklarını karşılamak için de uyarlanmaktadır.

Ailenin örgütsel sürecinde ikinci kilit nokta, aile üyeleri arasındaki duygusal ve yapısal destek, iş birliği ve bağl1lıktır. Birbirine bağlı ailelerde üyeler eğlence etkinlikleri ve ev işleri dahil olmak üzere birlikte vakit geçirerek ev içinde veya dışındaki katılımları paylaşmaktadır. $\mathrm{Bu}$ bağlamda birbirine bağlı aile üyelerinde duygusal yakınlık ve sadakat güçlüdür. Birlikte geçirilen zaman çok değerlidir ve birçok ilgi alanı, faaliyet ve arkadaşlıklar paylaşılmaktadır.

Ailenin örgütsel sürecinde diğer önemli etken sosyal ve ekonomik kaynakları harekete geçirmektir. Geniş akraba ve sosyal desteğe sahip olan ailelerin kriz dönemlerini atlatmalarına yardımcı olacak pratik yardım, duygusal destek ve topluluk kaynakları sağlanmaktadır. Ayrıca güvenlik ve dayanışma ile aidiyet duygusu hissettirilmektedir. Bu nedenle sosyal çevre ve sosyal destek aile dayanıklılı̆̆ında hayati öneme sahiptir. Aileler sorunlarını çözmekte yetersiz kaldıklarında, geniş aile, arkadaş, komşu, toplum hizmetleri ve/veya terapi veya danışma 
hizmetlerine yönelmektedir. Diğer yandan aile izolasyonu ve sosyal destek eksikliği, stres altında ailenin işlevsizliğine neden olabilmektedir.

Ayrıca ailenin zorluklar ve krizler karşısında esnek ve iyi bir organizasyon işleyişine sahip olması için ailede bir liderin olması gerekmektedir. Demokratik bir liderin kriz ve sorun anlarında aileyi ve bireyleri beslemede, yön göstermede ve korumada önemli bir etkisi bulunmaktadır. Bütün bunların aile içinde gerçekleşmesi için de ailenin birbirlerine olan bağlılıkları ve ilişkilerinin iyi olması gerekmektedir. Aile krizle karşılaştığında sağlıklı baş edebilmesi için karşılıklı desteğe, iş birliğine ve sadakate ihtiyaç duymaktadır.

\subsubsection{Ailenin İletişim Süreçleri: Karşılıklı Destek ve Problem Çözmeyi Kolaylaştırmak}

7. Açık ve tutarlı iletiler

- Açık, tutarlı mesajlar (kelimeler ve eylemler).

- Belirsiz ifadeleri netleştirmek; gerçeği aramak.

8. Duygusal paylaşım

- Acı veren hisleri paylaşmak (üzüntü, acı, öfke, korku, hayal kırıklı̆̆ı, pişmanlık).

- Olumlu duygu ve etkileşimleri paylaşma, zevk veren etkinliklerde bulunma, mizahı kullanma.

9. Ortak sorun çözme

- Yaratıcı beyin firtınası, beceriklilik.

- Ortak kararlar: Anlaşmazlıkları çözme, iş birliğine gitme ve adil olma.

- Hedeflere odaklanma, somut adımlar atma, başarı üzerinde durma, başarısızlıklardan öğrenme.

- Tepkiden motive edici duruşa geçiş: Gelecekteki zorluklara hazır olma, planlı olma, önleyici olma.

Wash (2016)'ya göre iyi bir iletişim, ailenin işleyiş ve dayanıklılığının tüm yönlerini kolaylaştırmaktadır. Kriz zamanlarında, zorlu geçişlerde veya uzun süreli stres durumlarında, iletişim aileler için oldukça önemli bir yere sahiptir. İletişim, inançların iletimini, bilgi alışverişini, duygusal ifadeyi ve problem çözme süreçlerini içermektedir.

Ailelerin problemlerle baş etme çabaları, durumlarını netleştirme yeteneklerini arttırmayı, birbirlerinin duygularını, ihtiyaçlarını ve kaygılarını ifade etmeyi, bunlara yanıt vermeyi, sorunları çözme ve yeni talepleri karşılama yaklaşımlarını müzakere etmeyi amaçlar. Açık bilgi, açık duygusal ifade ve işbirlikçi problem çözme ailenin dayanıklılığı için kilit süreçlerdir. Sayısız araştırma, iletişimde netliğin etkili çift ve aile işlevini kolaylaştırdığını söylemektedir (Beavers ve Hampson, 2003; Olson ve Gorall, 2003).

Ailenin iletişiminin iyi olmasını sağlayacak unsurlardan biri de aile üyelerin olumlu veya olumsuz duygularını açıkça ifade etmeleridir. Aile ortamında her üyenin olumlu veya olumsuz duygularını ifade etmesi, dürüst olması, bireyi ve aileyi güçsüzleştirmek yerine olumsuz yüklerin atılmasını sağlamakta ve aile üyelerini dayanıklı kılmaktadır. Açık ve net olarak duyguların ifade edilmesi bireyin ve ailenin krizler karşısında problem çözme becerilerini de olumlu yönde etkilemektedir (Walsh, 2016). Bu bağlamda ailelerin kriz anında dayanıklı olabilmeleri için belirsizliği netleştirmeleri ve açık olmaları gerekmektedir. 


\section{Sosyal Hizmet Uygulamalarında Aile Dayanıklılığı Yaklaşımın Önemi}

Aile dayanıklılığı yaklaşımın amacı, ailenin güçlü yönlerine ve potansiyeline odaklanarak, ebeveynleri ve geniş aile üyelerini destekleyici bir ekip çalışmasında işbirliği içinde yaşanan olumsuz etkileri azaltmak ve aile gelişimini desteklemektir.

Rutter (2006), dayanıklılı̆̆ 1 arttırmak için müdahalelerle güçlendirilebilecek genel koruyucu mekanizma tanımlamıştır. Şemalar aile sistemlerine uyarlanarak, aile dayanıklılığında kilit işlemlerin nasıl gerçekleştirileceği belirlenmektedir. Bunlar:

- Risk faktörlerini azaltma,

- Sürekli etki ve daha fazla kriz riskini artıran olumsuz tepkileri azaltma,

- Koruyucu aile süreçlerini güçlendirme ve güvenlik açıklarını azaltma,

- Problemleri başarılı bir şekilde çözerek aile ve bireysel gururu arttırmadır.

Aile dayanıklılığının kavramsallaştırması sistematik ve ilişkiseldir aynı zamanda ekolojik ve gelişimsel bağlamda etkileşimsel süreçleri de içermektedir. Bir ailenin dayanıklılığ incelendiğinde, aile ile çalışan sosyal hizmet uzmanları aile yapısını ailenin sosyo-kültürel çevre bağlamında anlamak için ekolojik ve gelişimsel perspektiften yararlanmaktadır.

Uygulamaya yönelik bir aile dayanıklılı̆̆ yaklaşımı, mevcut aile sistemleri modelleri ile birçok ortak noktalara sahiptir. Bunlar: işbirlikçi bir süreci vurgulamak, güçlü yönleri ve kaynakları belirlemek ve kaynak oluşturmak için çabalamaktır (Walsh, 2016). Travmatik olayların, yıkıcı geçişlerin ve son derece stresli koşulların ailelerin işleyişine ve üyelerin yaşadıkları zorlukların etkisine odaklanılmaktadır. Bu yaklaşım aynı zamanda, kırılganlık, risk ve dayanıklılık üzerindeki sosyo-kültürel, gelişimsel ve çok kuşaklı etkileri içermektedir. Müdahale çabaları, yaşamla ilgili zorluklarla baş etmede ailenin büyüme ve gelişmesini amaçlamaktadır.

Aile dayanıklılı̆̆ yaklaşımı, birbirinden farklı ailelerin aşırı stres altında nasıl hayatta kalabileceklerini ve kendilerini yeniden nasıl var edebileceklerini anlamaya çalışmaktadır. Ailelerin kendilerini iyileştirme ve kriz ve zorluklara rağmen büyüme potansiyelleri olduğunu ileri sürmektedir. Dayanıklı ailelerin yaşamın zorluklarına karşı koyabilme, yeniden toparlanabilme ve bu süreci etkili bir biçimde atlatabilme gücüne ve yeteneğine sahip olduklarını ileri sürmektedir. Dayanıklılıkta çeşitli yollar vardır, hiçbir ailenin ve durumun tek bir modeli yoktur. Girişimler önleme değerine sahiptir. Dayanıklılığı arttırmada aileler daha becerikli olmalı, gelecekteki zorlukları karşılamak için proaktif olmalıdır.

Aile dayanıklılı̆̆ çerçevesi, uygulayıcıları riskli durumlarda stresi ve kırılganlığ azaltabilecek kilit aile süreçlerini belirleme konusunda yönlendiren kavramsal bir harita olarak geliştirilmiş; krizi atlatıp iyileşmeyi, büyümeyi ve ailelerin uzun süreli sıkıntılarını aşmalarını teşvik etmek amaçlanmıştır.

Bu bağlamda ailelerle çalışan sosyal hizmet uzmanlarının öncelikle kriz olaylarının aile sistemine etkisini açığa çıkarması gerekmektedir. Aile süreçlerinin, aile uyumunun, aile ilişkilerinin tespit edilmesi diğer önemli bir husustur. Buna bağlı olarak ailelerin güçlü yönlerini açığa çıkarması, güçsüz yanlarını güçlü yanlara doğru kaydırması yani aileyi harekete geçirmesi gerekmektedir. Böylece ailenin zorluklara meydan okuyarak yeteneklerinin gelişmesine katk1 sağlanacaktır.

\section{Tartışma, Sonuç ve Öneriler}

Sonuç olarak ailelerle sosyal hizmet uygulaması gerçekleştirilirken aile dayanıklılı̆̆ının arttırılması üç aşamada belirtilen süreçlerin uygulanması ile gerçekleştirilebilecektir. Öncelikle, ailelerin; inanç sistemleri içinde, yaşanan zorlukların aileler için aynı şeyi ifade etmesi; buna göre kendilerine ve diğer üyelere ilişkin pozitif bir bakış açısı geliştirmeleri ve manevi ya da kültürel inançları ile içinde bulundukları durumla baş etmeye çalışmaları gerekmektedir. İkinci olarak aile üyelerinin örgütsel süreçler kapsamında; birbirlerine karşı esnek olmaları, karşılıklı 
destek ve iş birliği içinde olmaları ve sosyal ve ekonomik kaynakları harekete geçirecek güçte olmaları beklenmektedir. Son olarak iletişim süreçleri başlığı altında aile üyelerinin birbirleri ile açık ve tutarlı iletiler yoluyla, duygusal paylaşımları içeren ve ortak sorun çözme becerilerinin geliştiği bir yapıda olmaları gerekmektedir. Bu sayede zorluk yaşayan ailelerin mücadelecilik ruhları gelişecek, özyetkinlik becerileri artacak, yaşama bağlılıkları sağlanacak, aileler kendilerini kontrol edebilecekler ve böylece dayanıklılıkları artabilecektir.

Yapılacak çalışmalarda aile değerlendirmesi ve müdahaleleri ailenin içiyle sınırlı olmamalıdır. Ailenin engellerin üstesinden gelmek ve dayanıklılığı desteklemek için diğer sistem ve kaynaklarla olan ilişkileri de çalışmalara dahil edilmelidir.

\section{Kaynakça}

Beavers, W.R. ve Hampson, R.B. (2013). Measuring family competence: The beavers systems model. In F. Walsh (Ed.), Normal family processes $\left(3^{\text {rd }} \mathrm{ed}\right)$, New York: Guildford Press.

Black, K. ve Lobo, M. (2008). A conceptual review of family resilience factors. Journal of Family Nursing, 14(1), 33-55.

Bulut I. (1993). Ruh hastalığının aile işlevlerine etkisi, kadın ve sosyal hizmetler müsteşarlı̆̆g, (ss.158), Ankara: KSHM.

Collins, D., Jordan, C. ve Coleman, H. (2013). An introduction to family social work. Cengage Learning, Fourth Edition.

Duyan, V. (2003). Aileye yönelik planlı müdahale sürecinin aşamaları. Toplum ve Sosyal Hizmet Dergisi, 14 (1), 41-61.

Greene, R. R. ve Conrad, A. P. (2002). Basic assumptions and terms. In R. R. Grene (Eds), Resiliency: An integrated approach to practice, policy and research (ss. 29-62). Washington, DC: NASW Press.

Hawley, D. R. (2000). Clinical implications of family resilience. The American Journal of Family Therapy, 28, 101-116.

Kirst-Ashman, K.K. ve Hull Jr., G. H. (1999). Understanding generalist practice. Kongsbury, N; Scanzoni, J. (1993). Structural Functionalism. Boss,G.P.; Doherty, J.W.; LaRossa,R.; Schumm, R.W.; Steinmetz, K.S. (Ed.). Sourcebook of family theories and methods a countextual approach, (ss. 195-217). New York: Plenum Press.

Koşar, Nesrin G. (1992). Sosyal hizmetlerde aile ve çocuk refahı alanı. Ankara.

McCubbin, H.I., McCubbin, M.A., Thompson, A.I., Young Han, S. ve Allen, C.T. (1997). Families under stres: what makes them resilient. AAFCS Commemorative Lecture, Washington, DC.

McCubbin, H.I., Thompson, A.I., ve McCubbin, M.A. (1996). Family assessment: Resiliency coping and adaptation-Inventories for research and practice. Madison: University of Wisconsin System.

Olson, D. H. ve Gorall, D. M. (2003). Circumplex model of marital and family systems. In F. Walsh (Ed.), Normal family processes ( $\left.{ }^{\text {rd }} \mathrm{ed}\right)$, New York: Guildford Press.

Özgüven, İ.E. (2001). Ailede iletişim ve yaşam. Ankara: PDREM Yayınları.

Patterson, J. (2002). Integrating family resilience and family stress theory. Journal of Marriage and Family, 64, 349-360.

Rutter, M. (2006). Implications of resilience concepts for scientific understanding. Annals of the New York Academy of Sciences, 1094, 1-12. 
Simon, J.B., Murphy, J.J. ve Smith, S.M. (2005). Understanding and fostering family resilience.

The Family Journal: Counselling and Theraphy For Couples and Families, 13(4), 427-436.

Walsh, F. (2016). Strengthening family resilience (3 rd ed.). New York: Guilford Publications.

Werner, E.E. ve Smith, R.S. (2001). Overcoming the odds: High risk children from birth to adulthood. New York: Cornell University Press

Wright, L. M. ve Bell, J. M. (2009). Beliefs and illness. A model for healing. Calgary, Alberta, Canada: $4^{\text {th }}$ Floor Press.

Zastrow, C. (2015). Sosyal hizmete giriş. Ankara: Nika Yayınevi.

ETIKK ve BİLIMSEL İLKELER SORUMLULUK BEYANI

$\mathrm{Bu}$ çalışmanın tüm hazırlanma süreçlerinde etik kurallara ve bilimsel atıf gösterme ilkelerine riayet edildiğini yazar(lar) beyan eder. Aksi bir durumun tespiti halinde Afyon Kocatepe Üniversitesi Sosyal Bilimler Dergisi'nin hiçbir sorumluluğu olmayıp, tüm sorumluluk makale yazarlarına aittir. 